ISSN: 2231-3354

Received on: 21-06-2012

Revised on: 29-06-2012

Accepted on: 06-07-2012

DO: 10.7324/J APS.2012.2703

Manpret Kaur, Amendep Kaur and Ramica Sharma

Rayat I nstitute of P harmacy,

Railmajra, S. B. S. Nagar

Punjab, India.
For Correspondence Ms. Ramica Sharma Assistant Professor

Department of P harmacology Rayat I nstitute of Pharmacy

Railmaj ra, S. B. S Nagar.

Pin Code 144514

Contact N o. +91-08146556929

F ax- 188125001

\section{Pharmacological actions of Opuntia ficus indica: A Review}

\author{
Manpreet Kaur, AmandeepKaur and Ramica Sharma
}

\begin{abstract}
Cactus (Opuntia ficus-indica) belongs to the family Cactaceae. Family Cactaceae is reported to contain about 130 genera and nearly 1500 species. This plant is native of Mexico and it is widely distributed in Mexico and in all American hemispheres as well as in Africa and in the Mediterranean basin. It has been used in traditional folk medicine because of its role in treating a number of diseases and conditions, including anti-inflammatory effects hypoglycemic effects inhibition of stomach ulceration, neuroprotective effects Through antioxidant actions and also used for treating diabetes, burns, bronchial, asthma and indigestion in many countries over the world. It is also used in Pharma industry as a pharmaceutical agent. The fruit, as well as cactus stem are used to prepare value-added products, such as jam, squash, wine, pickle, body lotions, shampoo, creams, etc. It also has several medicinal and industrial uses. Its seeds can be used as flavouring agents. Due to the remarkable biological activity of Opuntia and its constituents, it will be appropriate to develop them as a medicine.
\end{abstract}

Keywords: Opuntia ficus indica, Cactus, flavonoid, pharmacological action.

\section{INTRODUCTION}

Cactus (Opuntia ficus-indica), commonly known as prickly pear, belongs to the family Cactaceae. Family Cactaceae is reported to contain about 130 genera and nearly 1500 species, which were originally native to the New World. Being so water-use efficient, they are highly useful in arid and semiarid environments, particularly during prolonged dry spells or failure of the monsoon (Singh, 2003). Locally it is called as nagphani or danda thohar. In Tamilnadu, it is commonly known as chapathi balli. It has different vernacular names in India like Hathlo thor, chorhthlo (Gujarati), Haththathoira, Nagphana, Nagphani (Hindi), Snuhi, Vajrakantaka, Bahushala (Sanskrit), Nagadali, Nagakkali, Chapati balli (Tamil), Nagamulla, Nagajemudu (Telugu), Nagphani, Thuar (Urdu) (Chauhan et al., 2011). The prickly cactus pear (Opuntia ficus-indica) is widely distributed in Mexico, much of Latin America, South Africa and the Mediterranean area (Hassan et al., 2011). 
It is widely distributed in Mexico and in all American hemispheres as well as in Africa and in the Mediterranean basin (Zorgui et al. 2009). Cactus is found wild in arid and semiarid plateau regions. It produces sweet, nutritionally rich edible fruits, its tender cladodes are used as fresh green vegetable and salad. The fruit, as well as cactus stem are used to prepare value-added products, such as jam, squash, wine, pickle, body lotions, shampoo, creams, etc. It also has several medicinal and industrial uses. Its seeds can be used as flavouring agents (Pareek et al. 2002).

It has been used in traditional folk medicine because of its role in treating a number of diseases and conditions, including antiinflammatory effects (Park et al, 1998), hypoglycemic effects (Frati et al, 1990), inhibition of stomach ulceration (Galati et al., 2003), neuroprotective effects (Dok-Go et al., 2003). Through antioxidant actions and also used for treating diabetes, burns, bronchial, asthma and indigestion in many countries over the world (Kim et al., 2006). One of the most frequently utilized fruit and vegetable technologies is juice production. Juices, in general, are a good source of sugars, vitamins and minerals; all valuable components to human health. The current food trend toward healthier diets makes juice consumption an important natural food alternative, and improves the availability of its nutritive compounds. Fruit and vegetable juices could play an important role in enhancing human health. In some countries, e.g., Chile, cactus pear juice is consumed at home, in vegetarian restaurants, or in local health-food store. However, due to certain technological problems associated with its production, no commercial products are produced at the industrial level (Zorgui et al., 2009) It was found that cacti in India did not all belong to one species, i.e., Opuntia dillenii, but three to four species distributed over different regions in India. O. dillenii Haw is found mainly in the southern parts of the India, while Opuntia vulgaris Mill. (Syn Opuntia monocantha Haw) was distributed mainly in the northern parts; Opuntia elatior Mill. was found in western India.

\section{Chemical composition}

Plant mucilage contains D-glucose, D-galactose, Larabinose, D-xylose, L-rhamnose and D-galacturonic and glucuronic acids (Samahy et al., 2006). Opuntia indica contain protein of molecular mass of $6.5 \mathrm{kDa}$ and was isolated by a combination of gel filtration chromatography and reverse-phase HPLC (Uchoa et al., 1998). Further determination of the sugars showed that hexoses are present $8-85 \% \mathrm{w} / \mathrm{w}$ and pentoses in $0.98 \%$ w/w. Although the flavonoid isorhamnetin and its glucoside are mentioned as the flavonoid components of the flowers however, penduletin, luteolin, kaempferol, quercetin, quercetin and rutin were isolated and identified. Other reports indicated that the plants of the Cactaceae family contain flavonol 3-O-glycosides (quercetin, kaempferol, and isorhamnetin), dihydroflavonols, flavonones, and flavanonols. Moreover, cactus pear fruit containing betalain pigments is a good potential for the use as a natural food colorant (Salim et al., 2009; Butera et al., 2002). Moreover, the fruits of Opuntia ficus indica are a source of ascorbic acid; in addition to ascorbic acid other organic acids were identified as maleic, malonic, succinic, tartaric and oxalic. Also contain appreciable amounts of vitamins B1, B6 vitamin E and vitamin A (Hassan et al., 2011). Opuntia ficus-indica fruit contains mineral also like calcium, magnesium, sodium and potassium, phosphorus, iron, (Salim et al., 2009).

\section{Traditional uses}

Opuntia ficus indica used as a folk medicine in Mexico for the treatment of burns, wounds, edema, and indigestion. It has been reported that its alcoholic extract possesses antiinflammatory, hypoglycemic, and anti-viral activities. Moreover in Mexico the prickly pear cactus stems have been used traditionally to treat diabetes. It has been also reported to medicinally used in hyperlipidemy (excess of lipids in the blood), and obesity (Saenz, 2000).

\section{Pharmacological activities}

\section{Anti-ulcer activity}

In Sicily folk medicine, Opuntia ficus indica (L.)Mill. cladodes are used for the treatment of gastric ulcer (Galati et al., 2001). Pre-treatment test in rats revealed a protective action against ethanol-induced ulcer (Galati et al., 2003). It was evident that acute administration of $\mathrm{O}$. ficus indica lyophilized cladodes generally maintains the cytoarchitecture of the gastric. The mucilage may prevent penetration of the necrotizing agent into the gastric mucosa. Moreover it forms a protective layer and prevents the deep necrotic lesions induced by ethanol (Trachtenberg and Mayer, 1981). The major components of O. ficus indica cladodes consist of a mixture of mucilage and pectin. The pectin polysaccharides from $O$. ficus indica cladodes probably may affect the gastrointestinal mucosa regeneration. $O$. ficus indica cladodes give rise to cytoprotection phenomena by breaking up the epithelial cells and stimulating an increase in mucus production in ethanol induce ulcer which tends to dissolve the components of the mucous membrane of the stomach and lowers the level of tissue protein, but preventive treatment with $\mathrm{O}$. ficus indica cladodes can stop the ulcerogenic agent to prevent damage (Galati et al., 2002)

\section{Anti-inflammatory activity}

Numerous studies have evocated the analgesic and antiinflammatory actions of the genus Opuntia by using either fruit extract, the lyophilized cladodes, or the phytosterols from fruit and stem extracts (park et al., 1998). Opuntia ficus indica has been reported to have anti-inflammatory activity. $\beta$-Sitosterol identified as the active anti-inflammatory principle from the stem extract though its activity appears to be relatively weaker compared with that of hydrocortisone (park et al., 2001). This is the first direct evidence on the anti-inflammatory activity of $\beta$-Sitosterol. Lyophilized aqueous extract (100-400 mg/kg, i.p.) of the fruits of Opuntia dillenii (Ker-Gawl) Haw was evaluated for analgesic activity using writhing and hot plate test in mice and rat, respectively and also anti-inflammatory activity using carrageenaninduced paw edema in rats, the results exhibited dose dependent action (Loro et al., 1999). 


\section{Neuroprotective}

Opuntia ficus-indica has been reported to have neuroprotective action in primary cultured rat cortical cells (DokGo et al., 2003). Opuntia ficus indica contains three flavonoid, quercetin, (+)-dihydroquercetin, and quercetin 3-methyl ether, are reported as active antioxidative neuroprotectants that exhibiting protective actions. It has been reported that Opuntia ficus indica shows protective action against the oxidative injury induced by $\mathrm{H}_{2} \mathrm{O}_{2}$, Xanthine/Xanthine Oxidase (X/XO), or Buthionesulfoximine (BSO) in primary cultured rat cortical cells, inhibiting lipid peroxidation, and scavenging DPPH radicals (Dok-Go et al., 2003). Moreover recently reported that quercetin, a component of Opuntia ficus-indica, had a neuroprotective action against $\mathrm{N}$ methyl-d-aspartate (NMDA), kainate (KA), and oxygen-glucose deprivation (OGD)-induced neurotoxicity in cultured rat cortical cell and in vivo global ischemia induced cultured gerbils cortical cells, (Ha et al., 2003). Methanol extract of Opuntia ficus-indica (MEOF) has a neuroprotective action against (NMDA), (KA), and (OGD)-induced neuronal injury in cultured mouse cortical cells and also reported the neuroprotective effect of MEOF in the hippocampal against neuronal damage evoked by global ischemia in gerbils (Kim et al., 2006).

\section{Anticancer activity}

Recent studies suggests that the cactus pear fruit extract (i) inhibits the proliferation of cervical, ovarian and bladder cancer cell lines in vitro, and (ii) suppresses tumor growth in the nude mice ovarian cancer model in vivo. These experiments showed that inhibition was dose- $(1,5,10$ and $25 \%$ cactus pear extract) and time- (1, 3 or 5 day treatment) dependent on in vitro-cultured cancer cells. The intra-peritoneal administration of cactus extract solution into mice did not affect the animal body weight, which indicated that cactus did not have a significant toxic effect in animals. Growth inhibition of cultured-cancer cells was associated with an increase in apoptotic cells and the cell cycle arrest at the G1-phase. Moreover, the induced growth inhibition seems dependent on the P53 pathway, which is the major tumor suppressor. Annexin IV was increased and the VEGF decreased in the tumor tissue obtained from animals having received the cactus solution. The antiproliferative effect of betanin, isolated from the fruits of Opuntia ficus indica, was evaluated on human chronic myeloid leukemia cell line (K562). The results show dose and time dependent decrease in the proliferation of K562 cells treated with betanin with an IC50 of $40 \mu \mathrm{M}$. Further studies involving scanning and transmission electron microscopy revealed the apoptotic characteristics such as chromatin condensation, cell shrinkage and membrane blebbing. Agarose electrophoresis of genomic DNA of cells treated with betanin showed fragmentation pattern typical for apoptotic cells. Flow cytometric analysis of cells treated with 40 $\mathrm{mM}$ betanin showed $28.4 \%$ of cells in sub G0/G1 phase. Betanin treatment to the cells also induced the release of cytochrome c into the cytosol, PARP cleavage, down regulation $\mathrm{Bcl}-2$, and reduction in the membrane potentials. These studies demonstrate that betanin induces apoptosis in K562 cells through the intrinsic pathway and is mediated by the release of cytochrome $\mathrm{c}$ from mitochondria into the cytosol, and PARP cleavage. The mechanisms responsible for executing the antiproliferative effects include: (i) induction of alterations in the cell differentiation pattern, which plays a vital role in the invasiveness and metastatic progression of the tumors, (ii) blockade of pre neoplastic cell expansion or induction of apoptosis, and (iii) intervention of metabolic activation of carcinogens by scavenging ROS (Loro et al., 1999; Sreekanth et al., 2007).

\section{Anti-viral activity}

An interesting study by Ahmad et al. demonstrated that administration of a cactus stem extract (Opuntia streptacantha) to mice, horses, and humans inhibits intracellular replication of a number of DNA- and RNA-viruses such as Herpes simplex virus Type 2, Equine herpes virus, pseudorabies virus, influenza virus, respiratory syncitial disease virus and HIV-1. An inactivation of extra-cellular viruses was also reported by the same authors. However, the active inhibitory components of the cactus extract used in this study was not investigated, and as of yet, no further study dealt with this specific topic (Ahmad et al., 1996)

\section{Alcohol Hangover}

Opuntia ficus indica also reported to useful in symptoms of alcohol hangover in humans. The cause of severity of the alcohol hangover may be inflammation induced by impurities in the alcohol beverage and byproducts of alcohol metabolism. An extract of the Opuntia ficus indica (OFI) plant diminishes the symptoms of alcohol hangover like nausea, dry mouth, and anorexia in humans (Wiese et al., 2004).

\section{Anti-diabetic property}

The present study was carried out to investigate the nutritional value, antioxidant activity and the effect of cactus pear (Opuntia ficus-indica) fruit juice on biochemical parameters, enzyme activities and lipid peroxidation in alloxan-induced diabetic rats. Alloxan was administrated as a single dose (130 $\mathrm{mg} / \mathrm{Kg} \mathrm{BW}$ ) to induce diabetes. A single or repeated dose of cactus fruit juice $(5 \mathrm{ml}$ per once, twice, three or four times/rat) was orally administrated daily to alloxan-induced diabetic rats for five weeks. The levels of glucose, cholesterol, urea, creatinine, aspartate aminotransferase (AST), alanine aminotransferase (ALT), alkaline phosphatase (ALP) and malondialdehyde (MDA) were significantly $(\mathrm{P}<0.05)$ increased, while levels of superoxide dismutase (SOD), reduced glutathione (GSH), HDL cholesterol, protein, hemoglobin and liver glycogen were significantly decreased in serum of alloxan induced diabetic rats. Treatment of the diabetic rats with single or repeated dose of cactus fruit juice could restore the changes of the above parameters to their normal levels (Hassan et al., 2011).

\section{Hepatoprotective}

Opuntia ficus indica cladodes extract also have protective effect against liver damage induced in mice by an 
organophosphorous insecticide, the chlorpyrifos (CPF). Liver damage was evaluated by the measure of its weight and the quantification of some biochemical parameters, such as alanine amino transferase (ALAT), aspartate amino transferase (ASAT), phosphatase alkaline (PAL), lactate dehydrogenase (LDH), cholesterol and albumin in serum by spectrophotometric techniques. It has been showed that CPF affects significantly all parameters studied. However, when this pesticide was administrated associated to cactus, we noticed a recovery of all their levels. Thus Opuntia ficus indica stem extract protects the liver and decreases the toxicity induced by this organophosphorous pesticide (Ncibi et al., 2008).

\section{Antioxidant property}

Ethanol extract of the stem of Opuntia ficus-indica var. saboten (OFS) was assessed to determine the mechanism(s) of its antioxidant activity. The ethanol extract exhibited a concentrationdependent inhibition of linoleic acid oxidation in a thiocyanate assay system. In addition, the OFS extract showed dose-dependent free-radical scavenging activity, including DPPH radicals, superoxide anions $\left(\mathrm{O}^{*}{ }^{*}\right)$, and hydroxyl radicals $\left(\mathrm{OH}^{*}\right)$, using different assay systems. The OFS ethanol extract was also found to be effective in protecting plasmid DNA against the strand breakage induced by hydroxyl radicals in a Fenton's reaction mixture. Furthermore, the extract showed significant $(\mathrm{p}<0.01)$ dosedependent protection of mouse splenocytes against glucose oxidase-mediated cytotoxicity. Finally, the OFS extract was characterized as containing a high amount of phenolics (180.3 $\mathrm{mg} / \mathrm{g}$ ), which might be the active compounds responsible for the antioxidant properties of the OFS extract (Lee et al., 2002).

\section{ACKNOWLEDGEMENT}

I am highly thankful to Management and Chairman of our college S. Gurwinder Bahra and S. Nirmal Singh Rayat for their co-operation and providing me scientific facilities.

\section{REFERENCE}

Ahmad A, Davies J, Randall S, Skinner GR. Antiviral properties of extract of Opuntia streptacantha. Antiviral Res. 1996; 30: 75-85.

Butera D, Tesoriere L, Gaudio FD, Bongiorno A, Mario A, Pintaudi AM, Kohen R, And Livrea M A. Antioxidant Activities Of Sicilian Prickly Pear (Opuntia Ficus Indica) Fruit Extracts And Reducing Properties Of Its Betalains: Betanin And Indicaxanthin. J. Agric. Food Chem. 2002; 50: 6895-6901.

Chauhan SP, Sheth NR, Jivani NP, Rathod IS, Shah PI. Biological actions of Opuntia species. Syst Rev Pharm. 2011; 1(2): 146151

Dok-Go H, Lee KH, Kim HJ, Lee EH, Song JLY, Lee YH, Jin C et al., Neuroprotective effects of antioxidative flavonoid, quercetin, (1)dihydroquercetin and quercetin 3-methyl ether, isolated from Opuntia ficus-indica var. saboten. Brain Research 2003; 965: 130-136.

El-Samahy S K, El-Hady EAA, Habiba RA, and Moussa TE. Chemical and Rheological Characteristics of Orange-Yellow Cactus-Pear Pulp from Egypt. J. PACD. 2006; 39-51.
Frati AC, Jiminez E, Ariza CR. "Hypoglycemic effect of Opuntia ficus-indica in Non-Insulin-dependent Diabetes Mellitus patients". Phytotherapy Research. 1990; 4(5): 195-197.

Galati EM, Monforte MT, Tripodo MM, d'Aquino A, Mondello MR. Antiulcer activity of Opuntia ficus indica (L.) Mill. (Cactaceae): ultrastructural study. Journal of Ethnopharmacology. 2001; 76: 1-9

Galati E M., S. Pergolizzi, N. Miceli, M.T. Monforte, M.M. Tripodo. Study on the increment of the production of gastric mucus in rats treated with Opuntia ficus indica (L.) Mill. Cladodes. Journal of Ethnopharmacology. 2002; 83: 229-233.

Galati, E.M., Mondello, M.R., Giufferida, D., Dugo, G., Miceli, N., Pergolizzi, S., Taviano, M.F. Chemical characterization and biological effects of Sicilian Opuntia ficus indica (L.) Mill. Fruit juice: antioxidant and antiulcerogenic activity. J. Agric. Food Chem. 2003; 51: 4903-4908

Hassan F, El-Razek A and Hassan AA. Nutritional Value and Hypoglycemic Effect of Prickly Cactus Pear (Opuntia Ficus-Indica) Fruit Juice in Alloxan-Induced Diabetic Rats. Australian Journal of Basic and Applied Sciences. 2012;5(10): 356-377, 2011

Kim JH, Park SM, Ha HJ, Moon CJ, Shin TK, Kim JM, Lee NH et al., Opuntia ficus-indica attenuates neuronal injury in in vitro and in vivo models of cerebral ischemia. Journal of Ethnopharmacology 2006; 104: 257-262

Lee JC, Kim HR, Kim J, and Jang YS. Antioxidant Property of an Ethanol Extract of the Stem of Opuntia ficus-indica var. Saboten. J. Agric. Food Chem. 2002; 50: 6490-6496.

Loro JF, Rio I, Perez-Santana L. Preliminary studies of analgesic and anti-inflammatory properties of Opuntia dillenii aqueous extract. J Ethnopharmacol 1999; 67: 213-8

Ncibi S, Othman MB, Akacha A, Krifi MN, Zorgui L. Opuntia ficus indica extract protects against chlorpyrifos-induced damage on mice liver. Food and Chemical Toxicology. 2008; 46: 797-802

Pareek OP, Singh RS and Vashishtha BB. Performance of Cactus Pear [Opuntia ficus-indica (L.) Mill.] Clones in Hot Arid Region of India. J. PACD. 2003, 2; 121-130.

Park, E.H., Kahng, J.H., Paek, E.A. Studies on the pharmacological actions of cactus: identification of is anti-inflammatory effect. Arch. Pharm. Res. 1998; 21: 30-34.

Park EH, Kahng JH, Lee SH, Shin KH. An anti-inflammatory principle from cactus. Fitoterapia, 2001;72:288-290

Salim N, Abdelwaheb C, Rabah C and Ahcene B. Chemical composition of Opuntia ficus-indica (L.) fruit. African Journal of Biotechnology. 2009; 8 (8): 1623-1624

Singh G. General Review of Opuntias in India. J. PACD - 2003,

$30-46$

Saenz C. Processing technologies: an alternative for cactus pear (Opuntia spp.) fruits and cladodes. Journal of Arid Environments 2000 46: 209-225

Sreekanth D, Arunasree MK, Roy KR, Reddy TC, Reddy GV, Reddanna P. Betanin a betacyanin pigment purified from fruits of Opuntia ficus-indica induces apoptosis in human chronic myeloid leukemia Cell line-K562. Phytomedicine 2007; 14: 739-46.

Trachtenberg S, Mayer, A.M. Composition and properties of Opuntia ficus indica mucilage. Phytochemistry. 1981; 20: 2665-2668

Uchoa AF, Souza PAS., Zarate RML, Gomes-Filho E. and Campos FAP. Isolation and characterization of a reserve protein from the seeds of Opuntia ficus-indica (Cactaceae). Bsi-oinlodgicicaal Research. 1998; 31: 757-761.

Wiese J, MD; McPherson S MD; Odden MC BS; Shlipak M G, MD, MPH. Effect of Opuntia ficus indica on Symptoms of the Alcohol Hangover. ARCH INTERN MED. 2004; 164: 1334-1340

Zorgui L, Golli EE, Bouaziz C, Bacha H, Hassen W. Cactus (Opuntia ficus-indica) cladodes prevent oxidative damage induced by the mycotoxin zearalenone in Balb/C mice. Food and Chemical Toxicology. 2008,$46 ; 1817-1824$ 